\title{
PRINTABILITY CHARACTERISTICS OF PAPER MADE FROM A JAPANESE KNOTWEED
}

\author{
Gregor Lavrič $^{1}$ (D), Tanja Pleša ${ }^{1}$ (D), Ana Mendizza ${ }^{2}$ (D), \\ Maruša Ropret $^{2}$ (D), Igor Karlovits ${ }^{1}$ (D), Diana Gregor-Svetec ${ }^{2}$ (iD) \\ ${ }^{1}$ Pulp and Paper Institute, Ljubljana, Slovenia \\ ${ }^{2}$ University of Ljubljana, Faculty of Natural Sciences and Engineering, Ljubljana, Slovenia
}

\begin{abstract}
Cereal straw and bagasse are presently the leading non-wood plants used in production of paper, though many fast-growing perennial plants have been studied for their suitability for paper manufacturing, too. In the present study the use of Japanese knotweed, as one of the most invasive alien plant species in Slovenia, as alternative raw material for papermaking is demonstreted. Paper was made of 55\% Japanese knotweed and sulfate cellulose produced from $60 \%$ eucalyptus and $40 \%$ conifer fiber. The paper with the basic weight of $90 \mathrm{~g} / \mathrm{m}^{2}$ was manufactured on the pilot paper machine at the Pulp and Paper Institute. Among printability characteristics paper brightness, colour, yellowness, roughness, air permeability, specular gloss, print penetration, picking, and print unevenness were determined. The preliminary research has shown, that Japanese knotweed, as a cheap local raw material, could be used in paper making industry, though the fiber processing and paper making process must be improved in order to obtain good printability.
\end{abstract}

Key words: graphic paper, Japanese knotweed, printability characteristics

\section{INTRODUCTION}

A vast number of plants represent potential sources of paper fibers. Many of them were used experimentally, some of them commercially, mostly on a small scale, at various times and places (Britt, 1964). They still are used mainly in forest deficient countries, but also elsewhere as alternative fiber source for production of all kind of papers (Novak, 2004). In countries where wood is unavailable in sufficient quantities non-wood annual plants and agricultural residues are becoming important raw materials (Obi Reddy et al, 2014). Cereal straw and bagasse are presently the leading non-wood plants used in production of paper, followed by reeds and bamboo, though many fast-growing perennial plants, such as prairies and tropical grasses, leaf fibers from tropical plants have been studies for their suitability for paper manufacturing, too (Obi Reddy et al, 2014; Biermann, 1996). Compared to wood sources, nonwood plants and agricultural residues offer several advantages including short growth cycles, moderate irrigation, and fertilization requirements and low lignin content, resulting in reduced energy and use of milder chemicals during pulping (Saikia et al, 1997). Certain fast growing plants are seen as invasive alien plant species. They are a big challenge in the European ecosystem, because they displace local vegetation, destroy agricultural land and cause damage to European economy, as they are mostly daily removed and burned. One of the most invasive alien plant species in Slovenia is Japanese knotweed. Japanese knotweed is a fast-growing and strong clump-forming perennial, with tall, dense annual stems. It has hollow stems with distinct raised nodes that give it the appearance of bamboo, and they may reach a maximum height of 3-4 m each growing season (Royal Horticultural Society, 2018). In the European project the use of Japanese knotweed, as alternative raw material for papermaking is researched, with the goal to define a first small-scale industrial process of paper production from Japanese knotweed.

Besides mechanical properties, printability is one of the most important paper characteristics. It tells us how paper behaves during a printing process. Printability depends on the interactions between the paper and printing ink at the given printing process variables. The print quality is strongly affected by the inkpaper interactions, an uneven absorption and distribution of ink components is one of the primary causes for defects, such as unevenness and mottle (Rousu et al, 2003). In the present research, a paper made from Japanese knotweed is described, with the emphasis on its printability characteristics.

\section{METHODS}

Paper was made of 55\% Japanese knotweed using only plant stem as fibre source. The sulphate process was used in order to remove lignin. The sulphate cellulose produced from $60 \%$ eucalyptus and $40 \%$ 
conifer fibers was added to Japanese knotweed. The paper with the basic weight of $90 \mathrm{~g} / \mathrm{m}^{2}$ was made on the pilot paper machine at the Pulp and Paper Institute. In the Figure 1 the Japanese knotweed plant and chopped stems are presented (Mežnarič Osole et al, 2015).
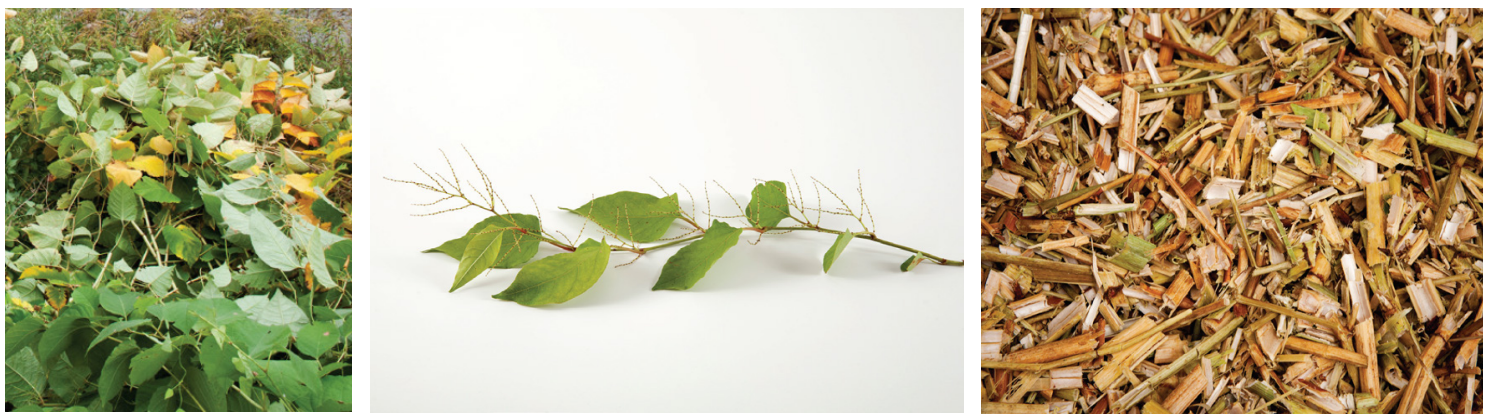

Figure 1: Japanese knotweed and chopped stems

Paper samples were conditioned in a standard atmosphere according to standard ISO 187, at the temperature of $23^{\circ} \mathrm{C}$ and relative humidity of $50 \%$. The basic paper properties: basic weight (ISO 536), thickness and density (ISO 534), moisture content (ISO 287) were determined according to standardised methods. An optical microscope Leica S9i was used to take a picture of the paper surface. The surface roughness and porosity were determined using Bendtsen roughness and air permeability tester (ISO 8791-2, ISO 5636-2). Water absorptiveness was assessed as Cobb value (ISO 535). Among optical properties ISO brightness (ISO 2470), yellowness (DIN 6167), opacity and transparency (ISO 2471), absorption and scattering (ISO 9416), specular gloss (ISO 8254-1) were determined on felt (A) and wire (B) side. Among colorimetric properties, the CIELAB colour coordinates $L^{*}, a^{*}, b^{*}$, chroma $C^{*}$ and hue $h$ were measured. Print penetration was determined according to IGT W24 method and pick velocity according to ISO 3783. For picking or pick velocity we have used the middle viscous picking oil which has a value of 48 Pas. The print unevenness was determined with the image processing using GLCM (Gray Level Co-Occurrence Matrix) based texture features. The full tone prints were done one Pruefbau printability tester using offset test inks with process parameters of $200 \mathrm{~N}, 0,3 \mathrm{~cm}^{3}$ ink quantity and printing speed of $1 \mathrm{~m} / \mathrm{s}$. The samples were dried for 24 hours to enable chemical drying and allow time for ink levelling out and the prints were scanned in 300 spi. For the image processing we have used the GLCM option of the radiomics package for $\mathrm{R}$ programming language. The samples were averaged from 4 angles $\left(0^{0}, 45^{\circ}, 90^{\circ}, 135^{\circ}\right)$ with an offset of 1 pixel.

\section{RESULTS AND DISCUSSION}

In Table 1 the basic properties of paper are presented. Low density of paper results from the absence of any filler added and from the brought distribution of fiber dimensions, resulting in poorer alignment of fibers and web connectivity. High standard deviation for thickness and density of paper suggest that paper is less homogeny, with higher variation in thickness and density as papers obtained from the wood fibres.

Table 1: Basic properties of paper given as mean value and standard deviation

\begin{tabular}{|l|c|c|c|c|}
\hline Sample & Basic weight $\left(\mathrm{g} / \mathrm{m}^{2}\right)$ & Thickness $(\mu \mathrm{m})$ & Density $\left(\mathrm{kg} / \mathrm{m}^{3}\right)$ & Moisture content $(\%)$ \\
\hline Paper from JK & $90.9 \pm 2.37$ & $157 \pm 19.15$ & $586.2 \pm 76.91$ & $4.73 \pm 0.22$ \\
\hline
\end{tabular}

In Table 2 surface and optical properties of paper are presented. High value of surface roughness and air permeability show that paper is less dense, whit high porosity and surface unevenness. Despite of high air permeability and low density, water absorptiveness is low, meanly because sizing agents were added in the paper production process. Low value of lightness and ISO brightness, beside positive values of colour coordinates $a^{*}$ and $b^{*}$ tell us, that paper has "natural" yellow look. That is confirmed with the quite high value of yellowing index. As bleaching of fibres was not applied obtained values were expected. Both values of scattering and absorption coefficient are in the range of unbleached chemical pulp. A high surface roughness coincides with a low value of specular gloss. The measurements on felt and wire side revealed the only noticeable difference in surface roughness. 
Table 2: Surface and optical properties of felt and wire side of paper

\begin{tabular}{|l|c|c|}
\hline Properties & Felt side & Wire side \\
\hline Water absorptiveness $\mathrm{C}_{60}\left(\mathrm{~g} / \mathrm{m}^{2}\right)$ & 12.01 & 16.84 \\
\hline Surface roughness $(\mathrm{ml} / \mathrm{min})$ & 2080 & 1820 \\
\hline Air permeability $(\mathrm{ml} / \mathrm{min})$ & 540 & 540 \\
\hline ISO brightness (\%) & 39.88 & 39.40 \\
\hline Yellowness (\%) & 35.70 & 36.04 \\
\hline Florescence (\%) & 0.26 & 0.02 \\
\hline Opacity (\%) & 98.94 & 98.59 \\
\hline Transparency (\%) & 8.51 & 9.62 \\
\hline Absorption coefficient $\left(\mathrm{m}^{2} / \mathrm{kg}\right)$ & 7.06 & 6.97 \\
\hline Scattering coefficient $\left(\mathrm{m}^{2} / \mathrm{kg}\right)$ & 35.81 & 35.14 \\
\hline Specular gloss (\%) & 4.33 & $/$ \\
\hline $\mathrm{L}^{*} / \mathrm{a}$ / $\mathrm{b}^{*}$ & $78.01 / 2.41 / 16.22$ & $77.86 / 2.47 / 16.35$ \\
\hline $\mathrm{C}^{*} / \mathrm{h}$ & $16.40 / 81.54$ & $16.53 / 81.41$ \\
\hline
\end{tabular}

In Table 3 some of the printing properties that were determined are presented. The picking of paper is defined as the damage of the paper surface caused by tensile force during the printing operation. The pick velocity is defined as the velocity at which picking starts. Higher is the surface strength of the paper, the higher is velocity. The pick velocity around $2 \mathrm{~m} / \mathrm{s}$ is for uncoated paper adequate. Viscosity velocity product (VVP) with the value around 100 confirms, a good pick resistance of paper. Good surface strength was influenced by the type of fibres, where the presence of long fibres improved the strength, by the treatment of fibres and proper surface sizing.

Low print gloss means that ink has poor reflective properties. It is related to excessive ink penetration into the paper and high surface roughness. Print penetration is related to absorption, roughness and porosity of paper surface. A rather high value of print penetration obtained is the result of high oil absorptiveness and porosity of paper surface.

Table 3: Printing properties of paper given as mean value and standard deviation

\begin{tabular}{|l|c|c|c|}
\hline Sample & Pick velocity $(\mathrm{m} / \mathrm{s})$ & Print penetration $(1000 / \mathrm{mm})$ & Print gloss $(\%)$ \\
\hline Paper from JK & $2.03 \pm 0.19$ & $30.74 \pm 0.95$ & $2.93 \pm 0.08$ \\
\hline
\end{tabular}

In Table 4 GLCM parameters, which describe the print unevenness are presented. The GLCM entropy is the measure of spatial disorder, and a high value obtained means that structure (texture) is less organized and the image is nonhomogeneous. GLCM values are dimensionless and in this case the entropy is rather high which indicates high mottling which can be also notices in Figure 1. GLCM Contrast is very dependent on the angle orientation of the inhomogeneous areas and this value indicates that is prominent in all directions.

Table 4: GLCM parameters of paper given as mean value and standard deviation

\begin{tabular}{|l|c|c|c|c|}
\hline Sample & GLCM energy & GLCM correlation & GLCM entropy & GLCM contrast \\
\hline Paper from JK & $0.0001 \pm 0.00002$ & $0.805 \pm 0.054$ & $9.203 \pm 0.141$ & $453.64 \pm 124.83$ \\
\hline
\end{tabular}
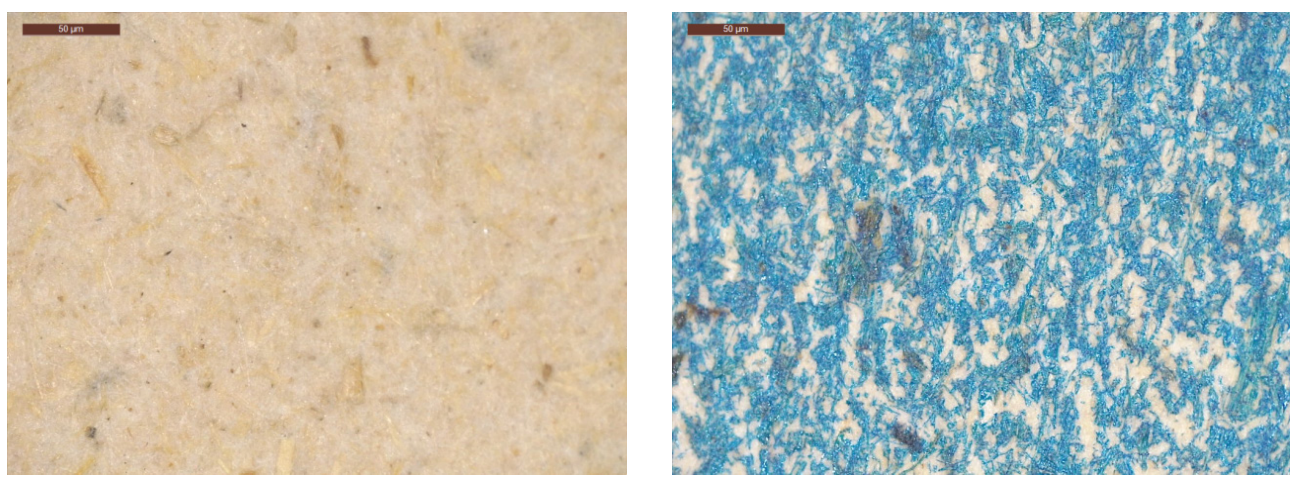

Figure 1: OM image of paper surface and print 


\section{CONCLUSIONS}

Paper obtained from Japanese knotweed was produced on a pilot paper machine, in order to access the possibility of producing a paper with the adequate properties from the annual plant residue. The roughness of the paper and porosity are quite high, and the specular gloss low, which could be improved with better refining of fibers, cleaning to remove impurities, by adding the filler and by calendaring. Good surface strength and low water absorptiveness are connected to appropriate level of sizing of paper surface. The higher unevenness of surface, and larger number of impurities present, resulted in mottling. The brightness of paper is quite low, also because lignin and extractives were not completely removed in the fiber processing steps, and because no bleaching was applied.

The preliminary research has shown, that Japanese knotweed, as a cheap local raw material, could be used in paper making industry. However, to reach good printability characteristics of paper, mainly the fiber processing must be improved.

\section{ACKNOWLEDGMENTS}

Research is a part of the project "APPLAUSE - Alien Plant Species from harmful to useful with citizens' led activities", which is co-financed by EU Regional Development Fund.

\section{REFERENCES}

[1] Biermann, C.J.: "Handbook of pulping and papermaking", $2^{\text {nd }}$ ed, (Academic Press, Inc., San Diego, USA, 1996), page 633.

[2] Britt, K.W.: "Handbook of pulp and paper technology", (Reinhold Publishing Corporation, New York, USA, 1964), page 44.

[3] Mežnarič Osole, G., Jelenec, N., Dekleva, K.: "A friendly enemy Japanese knotweed in the paper laboratory", (Ljubljana, SI: Muzej za arhitekturo in oblikovanje, 2015)

[4] Novak, G.: "Grafični materiali”, (Naravoslovnotehniška fakulteta, OT, Ljubljana, SI: Univerza v Ljubljani, 2004), page 67.

[5] Obi Reddy, K., Uma Maheswari, C., Shukla, M., Muzenda, E.: "Preparation, Chemical Composition, Characterization, and Properties of Napier Grass Paper Sheets", Separation Science and Technology 49(10), 1527-1534, 2014. doi: 10.1080/01496395.2014.893358.

[6] Rousu, S., Gane, P., Eklund, D.: "Distribution of offset ink constituents in paper coating and implication for print quality", Proceedings of TAPPI Advanced Coating Fundamentals, (Chicago, USA, 2003).

[7] Royal Horticultural Society, Japanese knotweed, Royal Horticultural Society, 2018, URL https://www.rhs.org.uk/advice/profile?PID=218 (last request: 2018-09-27).

[8] Saikia, S.N., Goswami, T., Ali, F.: "Evaluation of pulp and paper making characteristics of certain fast growing plants", Wood Science and Technology 31(6), 467-475, 1997. doi: 10.1007/BF00702569.

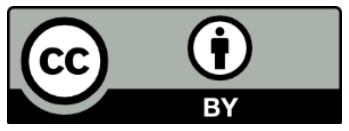

(C) 2018 Authors. Published by the University of Novi Sad, Faculty of Technical Sciences, Department of Graphic Engineering and Design. This article is an open access article distributed under the terms and conditions of the Creative Commons Attribution license 3.0 Serbia (http://creativecommons.org/licenses/by/3.0/rs/). 